\title{
Fomento de la seguridad alimentaria y nutricional y de la soberanía alimentaria en unidades de producción familiar del cantón de Siquirres, provincia de Limón
}

\author{
Promotion of Food and Nutritional Security and Food \\ Sovereignty in Family Production Units in the Canton of \\ Siquirres, Province of Limón, Costa Rica
}

\author{
Diego Aguirre Rosales \\ Universidad Nacional \\ Heredia, Costa Rica \\ diego.aguirre.rosales@una.cr \\ Amelia Aiza Ajoy \\ Universidad Nacional \\ Heredia, Costa Rica \\ ameaiza@gmail.com
}

Recibido: 01/02/2021 • Aceptado: 11/05/2021

Resumen. El proyecto se desarrolló en el cantón de Siquirres de la provincia de Limón. El proceso consistió en la capacitación, en aprender haciendo y en el diálogo de saberes para fomentar la producción de veinticinco cultivos de seguridad alimentaria y nutricional para promover la soberanía alimentaria en las unidades de producción de treinta y cuatro familias y una escuela del territorio rural marginal de dicho cantón. En este proceso se contó con la participación de dos organizaciones de productoras y productores, de instituciones públicas, de la Universidad Nacional y de estudiantes de los últimos niveles de la carrera de Ingeniería Agronómica de la Escuela de Ciencias Agrarias de la Universidad Nacional.

Palabras clave: soberanía alimentaria y nutricional, seguridad alimentaria, unidad de producción familiar. 


\begin{abstract}
The project was developed in Siquirres, a canton of the Limón province. The process consisted of training, learning by doing, and the dialogue of knowledge systems to promote the production of twenty-five food security and nutrition crops to promote food sovereignty in the production units of thirty-four families and a school in the marginal rural territory of the mentioned canton. The process included the participation of two organizations of producers, public institutions, the National University, and advanced students of the Agronomy career of the School of Agricultural Sciences of the National University.
\end{abstract}

Keywords: food and nutrition sovereignty, food security, family production unit.

\title{
Introducción
}

La Región Huetar Caribe (RHC) se caracteriza por ser un territorio del trópico húmedo, donde hay claramente una época muy marcada de lluvia en abundancia y otros meses que se pueden tipificar como secos. Esta condición determina que esta región sea muy rica para desarrollar una agricultura diversa de la zona, ya que posee suelos de excelente calidad y un régimen de lluvia apropiado, temperatura y brillo solar adecuados que permiten la producción de cultivos como raíces y tubérculos, musáceas, granos básicos, ornamentales, cucurbitáceas, plantas medicinales y frutas y se puede producir otra gran diversidad de alimentos.

Específicamente, las cualidades climáticas y edáficas existentes en el cantón de Siquirres de la provincia de Limón permiten validar otra agricultura poco explotada en la zona: las hortalizas. Estas hortalizas es posible producirlas bajo una estrategia agronómica de huerta familiar y escolar directo en el suelo, se puede producir pepino, tomate, lechuga, camote, chile, culantro, plantas medicinales, maíz, frijol, vainica, apio, ayote, árboles frutales y otra gran cantidad de alimentos, los cuales pueden llegar a mejorar la seguridad alimentaria y nutricional (SAN) y la soberanía alimentaria de las familias de esta región.

Como parte del proceso de extensión de la Universidad Nacional, la Escuela de Ciencias Agrarias planteó el proyecto denominado "Capacitación de los actores comunales de las organizaciones locales, municipales e institucionales para fortalecer la gestión del plan de desarrollo local del cantón de Siquirres 2016-2030 y para promover actividades productivas y de agronegocios".

Como parte de los objetivos de este proyecto, se plantea realizar una serie de actividades y acciones para fomentar veinticinco cultivos, con el fin de incentivar la seguridad alimentaria y nutricional y la soberanía alimentaria 
de treinta y cuatro familias, pertenecientes a la asociación de mujeres emprendedoras dedicadas a producir hortalizas y otros cultivos a baja escala en el distrito de Florida de Siquirres, a la asociación de personas productoras de San Pancracio (Asapan) del distrito Reventazón y a la Escuela Louisiana del distrito de El Cairo, una institución que promueve la huerta escolar para producir alimentos que suplen al comedor estudiantil.

\section{Objetivo general}

Promover, en forma coordinada con las instituciones públicas y la Escuela de Ciencias Agrarias de la Universidad Nacional, un proceso de fomento de la producción de cultivos de seguridad y soberanía alimentaria en familias de las poblaciones marginadas del área rural del cantón de Siquirres

\section{Objetivos específicos}

Fomentar veinticinco cultivos de seguridad y soberanía alimentaria en las unidades de producción familiar de treinta y cuatro familias y una escuela del territorio rural del cantón de Siquirres.

Articular acciones con el Ministerio de Agricultura y Ganadería, el Ministerio de Educación y la Universidad Nacional para fomentar uno de los principales objetivos: la inclusión de las familias en la producción de alimentos para mejorar la calidad de vida y generar una mayor igualdad de oportunidades de acceso a la cantidad y calidad de los alimentos.

\section{Marco teórico}

Los alimentos son uno de los principales productos que busca constantemente el ser humano, esto se debe a que la base de la humanidad desde tiempos ancestrales ha tenido que lograr el abastecimiento de sus poblaciones mediante la producción e innovación de estos.

El ser humano busca la manera de obtener alimentos con mayor valor nutricional, en mayores cantidades y de una manera mucho más rápida, esto se debe a que el aumento de las poblaciones impulsa a la innovación de la agricultura, las grandes ciudades crecen sin medida y el aumento de la tasa de natalidad supera con creces a la de mortalidad, por ello se dice que se va a observar un aumento de la necesidad de alimentos, que puede llegar a generar un incremento en el número de familias que pueden sufrir una inseguridad alimentaria. 
Revista Universidad en DiÁlogo • Vol. 11, N. ${ }^{\circ} 2$, Julio-Diciembre, 2021 • 161-173

ISSN 2215-2849 • EISSN: 2215-4752

URL: http://www.revistas.una.ac.cr/index.php/dialogo/index CorReo ElECTRÓNICO: universidadendialogo@una.cr

DOI: http://doi.org/10.15359/udre.11-2.8

Según la FAO, en países como Afganistán y Etiopía la data de pobreza aumenta entre $30 \%$ y $45 \%$ cada año, debido a los fuertes cambios de temperatura y las plagas que atacan los cultivos, induciendo a un aumento en los precios de los alimentos. Por ello se busca que más familias estén al frente de la batalla contra esta crisis alimentaria, ayudando en la producción de sus propios alimentos, para así lograr una mayor sostenibilidad que provoque una disminución en la demanda del mercado de alimentos.

En un informe de la FAO se señalan veintisiete países susceptibles de sufrir crisis alimentarias a causa de la COVID-19 (2020).

La unidad de producción familiar es el pilar de la agricultura, el problema que se ha venido generando es la falta de ayuda a esta, ya que, aunque la agricultura siempre se ha considerado una práctica familiar, las sociedades y el Gobierno no generan ayudas financieras que puedan ser solventes para las familias. Por ello, se considera que la sobrevivencia de la agricultura se dará si existen entes financieros que ayuden a fortalecer estos nichos agrícolas.

Otro problema que se ataca hoy día es la sobrealimentación, que ha venido en aumento; muchas poblaciones han alcanzado una subalimentación que provoca la inflación de la demanda alimenticia, esto es igual a una inflación en el precio de los mercados, ya que el aumento de la cantidad de alimentos provoca una competencia mayor.

Aun así, se sabe que este aumento no es equitativo, ya que para algunas personas se puede observar como un punto positivo a favor de la batalla contra el hambre, pero para otras la obtención de estos otros productos es casi imposible, empujando a las poblaciones a llevar una vida con un consumo de alimentos restringidos.

La prevalencia de la subalimentación entre el 2000 y el 2019 también se redujo en más de tres puntos porcentuales, de un $11,1 \%$ a un $7,4 \%$. Sin embargo, la prevalencia más baja se registró en el 2014, afectando al 5,6 \% de la población regional. A partir de ese año y hasta el 2019, el hambre aumentó casi dos puntos porcentuales y alcanzó un 7,4 \% en el 2019 (FAO, FIDA, OPS, WFP y Unicef, 2020).

Según el Instituto de Nutrición para Centroamérica y Panamá (Incap), la seguridad alimentaria nutricional es un estado en el cual todas las personas gozan, en forma oportuna y permanente, de acceso físico, económico y social a los alimentos que necesitan, en cantidad y calidad, para su adecuado consumo y utilización biológica, garantizando un estado de bienestar general que coadyuve al logro de su desarrollo (FAO, 2006). 
Según la vía campesina, promotora de la idea, la soberanía alimentaria es el derecho de los pueblos, las naciones o las uniones de países a definir sus políticas agrícolas y de alimentos, sin ningún dumping frente a países terceros. La soberanía alimentaria organiza la producción y el consumo de alimentos acorde con las necesidades de las comunidades locales, otorgando prioridad a la producción para el consumo local y doméstico. Proporciona el derecho a los pueblos a elegir lo que comen y de qué manera quieren producirlo.

La soberanía alimentaria incluye el derecho a regular la producción nacional agropecuaria y a proteger el mercado doméstico del dumping de excedentes agrícolas y de las importaciones a bajo precio de otros países. Reconoce así mismo los derechos de las mujeres campesinas. La gente sin tierra, el campesinado y la pequeña agricultura tienen que tener acceso a la tierra, al agua, a las semillas y los recursos productivos, así como a un adecuado suministro de servicios públicos. La soberanía alimentaria y la sostenibilidad deben constituirse como prioritarias en las políticas de comercio (FAO, 2006).

\section{Metodología}

El proyecto se desarrolló en el cantón de Siquirres, el cual se localiza en la provincia de Limón; esta provincia registra índices de desarrollo social muy bajos, lo cual determina una alta vulnerabilidad y desempleo muy elevados, esto debido a que la mayoría de sus habitantes se dedican a la agricultura y al empleo ocasional, como las horas de jornal en las bananeras de la zona.

Este proyecto se realizó con el apoyo participativo de tres grupos de pobladores de la zona de Siquirres, de las comunidades de Louisiana, San Pancracio y San Isidro de Siquirres.

Estos grupos fueron seleccionados por las condiciones de pobreza y su deseo de tener oportunidades de superación personal, debido a que son familias de muy bajos recursos y de territorios marginados.

También se tomaron en cuenta comunidades que ya tenían experiencia en el manejo de cultivos agrícolas o en algún tema relacionado con el sector agrario.

La asociación de mujeres emprendedoras que se dedicaba a producir hortalizas y otros cultivos a baja escala en el distrito de Florida de Siquirres, la asociación de personas productoras de San Pancracio (Asapan) del distrito Reventazón y la Escuela Louisiana del distrito de El Cairo, una institución que promueve la huerta escolar con cultivos para producir alimentos que suplen al comedor estudiantil, son las partes implicadas en este proyecto. 
El principal elemento de la metodología que se utilizó es el aprender haciendo directo a nivel de campo, por medio del diálogo de saberes entre las familias participantes de las comunidades, profesionales de las instituciones y estudiantes. Se desarrollaron talleres participativos y giras de campo de seguimiento y trabajo, en los cuales se realizaron actividades en conjunto con las comunidades ya mencionadas y se les capacitó en la realización de trabajos agrícolas en los que ya tenían alguna experiencia, ya que las familias tienen sus métodos de siembra, por lo que se respetó su manejo del cultivo.

El proceso de capacitación consistió en temas relacionados con la agroecología y la permacultura, enseñando métodos o prácticas de elaboración de abonos orgánicos, las cuales iban acompañadas de charlas en donde los y las participantes asistían y se les comentaba sobre algunas prácticas empleadas en este tipo de agricultura.

Estos intercambios por medio del diálogo de saberes crearon confianza y motivación, el peldaño fundamental para fomentar veinticinco diferentes tipos de cultivos en las unidades de producción, con el fin de promover la seguridad y soberanía alimentarias en las familias.

Esta experiencia debe permitir que se reproduzca en forma sostenible la semilla, aumentar el área de cultivo y, una vez que estén consolidados los sistemas de cultivos, que las familias puedan vender el excedente productivo como una estrategia de pequeños microagronegocios familiares.

\section{Resultados y discusión}

El trabajo se realizó con la premisa de que las familias produjeran sus propios alimentos y así generar una seguridad alimentaria y nutricional (SAN) y su soberanía alimentaria familiar.

Con la realización de este proyecto SAN se obtuvieron resultados que ayudaron en gran medida en la aceptación de las comunidades del fomento de prácticas más sostenibles y amigables con el medio ambiente, como el uso de la semilla autóctona, la capacitación en la elaboración y el uso de abono orgánico, la preservación con prácticas agrícolas para lograr la producción de alimentos saludables, el deber de reproducir la semilla para hacer el sistema de producción sostenible, promover el intercambio de productos y semillas entre familias y aumentar el área de producción, para que en una próxima etapa se pueda comercializar el excedente y generar ingresos. 
URL: http://www.revistas.una.ac.cr/index.php/dialogo/index

CORREO ELECTRÓNICO: universidadendialogo@una.cr

DOI: http://doi.org/10.15359/udre.11-2.8

En las Figuras 1, 2 y 3 se observa cómo reaccionaron las poblaciones meta y cómo con la ayuda de algunas prácticas guiadas se logró una producción de alimentos para promover el mejoramiento de la nutrición de las personas.

Según Rosset y Altieri (2018), la agroecología es la base de una agricultura sostenible, pero desde un aprendizaje sin reciprocidad y tolerancia hacia otras prácticas esta no tiene efectos positivos para poblaciones más sensibles a la economía.

En consideración con la experiencia del proyecto, el anterior concepto de agricultura sostenible se vio reflejado en los resultados obtenidos, aplicando la estrategia de aprender haciendo y el diálogo de saberes y prácticas de agricultura sin agroquímicos.

\section{Figura 1}

Imágenes de los resultados obtenidos de las comunidades de San Pancracio
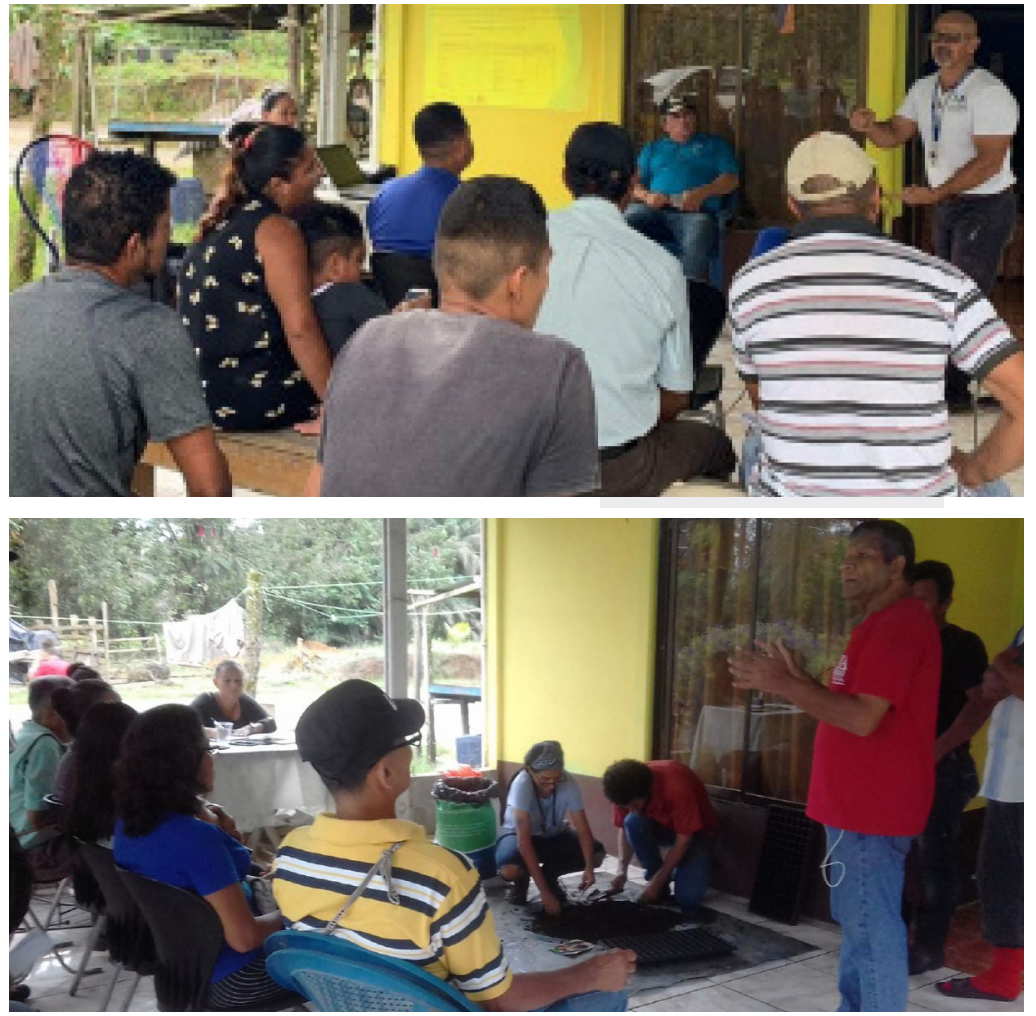

Nota. Imágenes propiedad de las personas autoras. 
Revista Universidad en DiÁlogo • Vol. 11, N. ํ 2, Julio-Diciembre, 2021 • 161-173

ISSN 2215-2849 • EISSN: 2215-4752

URL: http://www.revistas.una.ac.cr/index.php/dialogo/index CORREO ELECTRÓNICO: universidadendialogo@una.cr DOI: http://doi.org/10.15359/udre.11-2.8

El cantón de Siquirres tiene un índice de pobreza alto, las familias agricultoras requieren encontrar alternativas de productos agrícolas, ya que esta región tiene un aumento considerable de pobreza, pasando de un $20,2 \%$ en el año 2007 a un $24,7 \%$ en el año 2008 (Plan Regional de Desarrollo Agropecuario y Rural 2015-2018, 2015).

Los resultados del proyecto reflejan que es posible fomentar a mayor escala la producción de estos veinticinco cultivos que se validaron con las treinta y cuatro familias del cantón. En proyección, la comercialización de estos productos es posible, ya que se encuentra elaborado y en proceso de aprobación el proyecto de mercado para la Región Huetar Caribe. Lo cual vendría a solventar en gran medida el problema de desempleo y pobreza para las familias de dicho territorio.

\section{Figura 2}

Imágenes de los resultados obtenidos con la Asociación de Mujeres Emprendedoras de la Región de San isidro de Florida (Mesip)
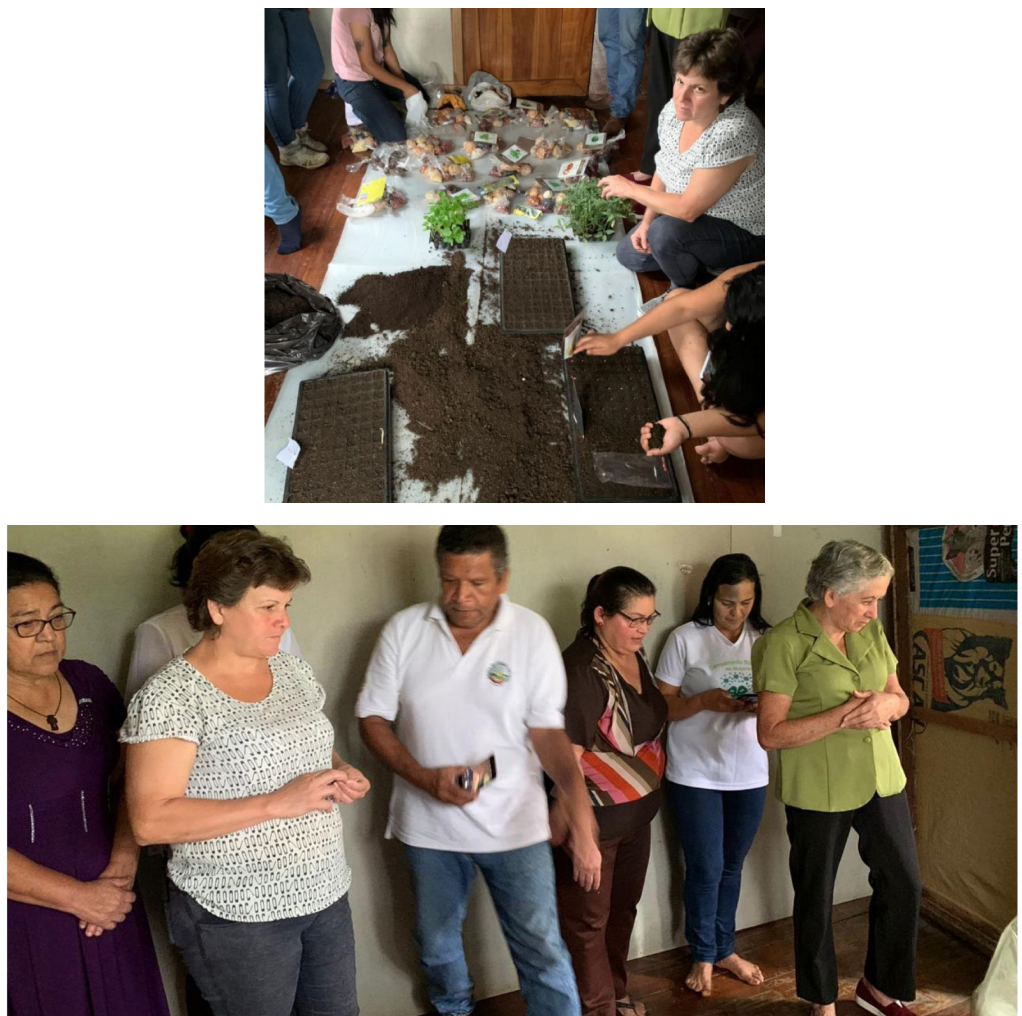

Nota. Imágenes propiedad de las personas autoras. 
URL: http://www.revistas.una.ac.cr/index.php/dialogo/index

CORREO ELECTRÓNICO: universidadendialogo@una.cr

DOI: http://doi.org/10.15359/udre.11-2.8

\section{Figura 3}

Imágenes de los resultados obtenidos en la huerta escolar de la Escuela Louisina del Cairo
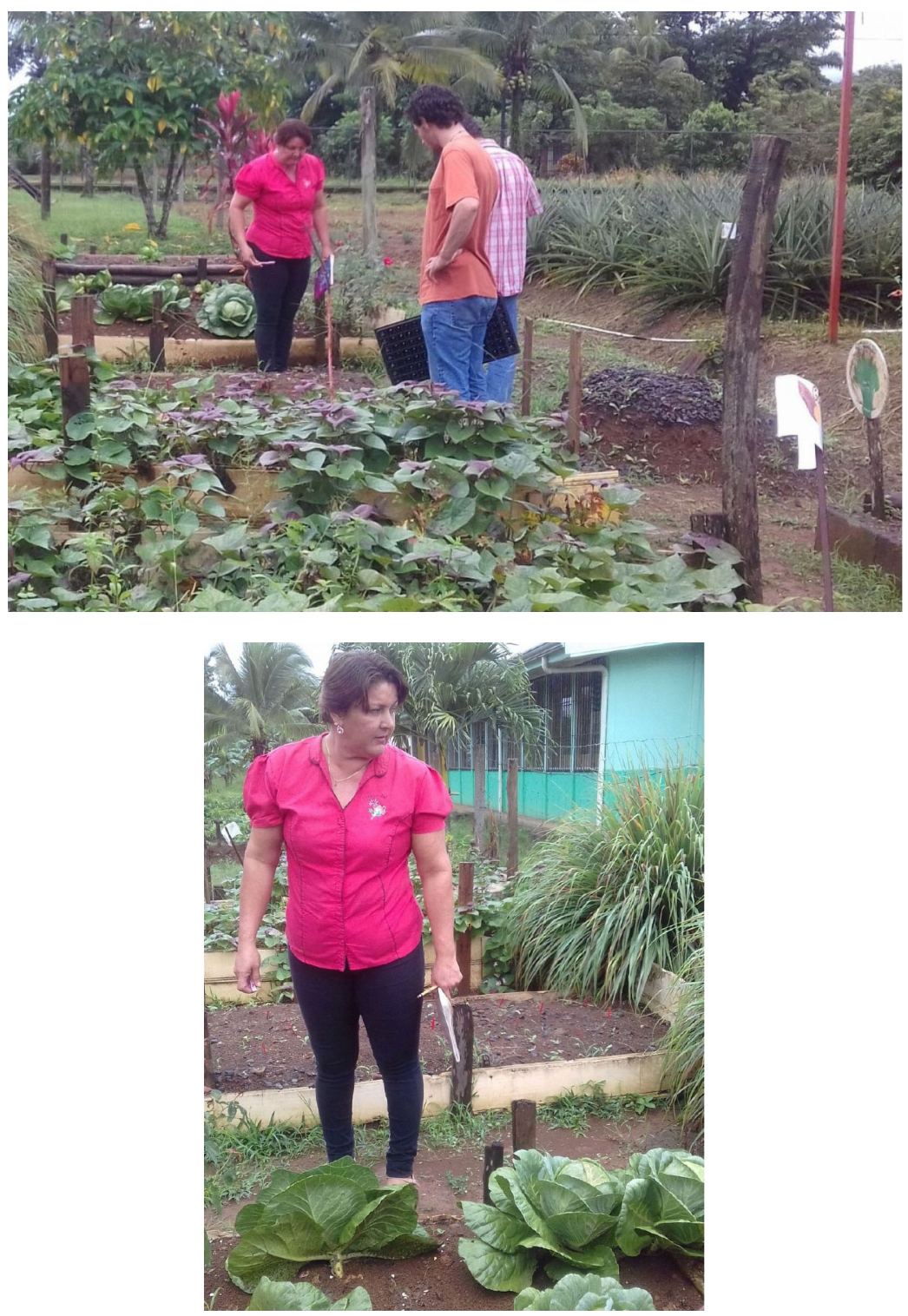

Nota. Imágenes propiedad de las personas autoras. 
Revista Universidad en Diálogo • Vol. 11, N. 2, Julio-Diciembre, 2021 • 161-173

ISSN 2215-2849 • EISSN: 2215-4752

URL: http://www.revistas.una.ac.cr/index.php/dialogo/index CORREO ELECTRÓNICO: universidadendialogo@una.cr DOI: http://doi.org/10.15359/udre.11-2.8

\section{Figura 4}

Resultados obtenidos en la zona indígena de Talamanca Ángeles Cabécar
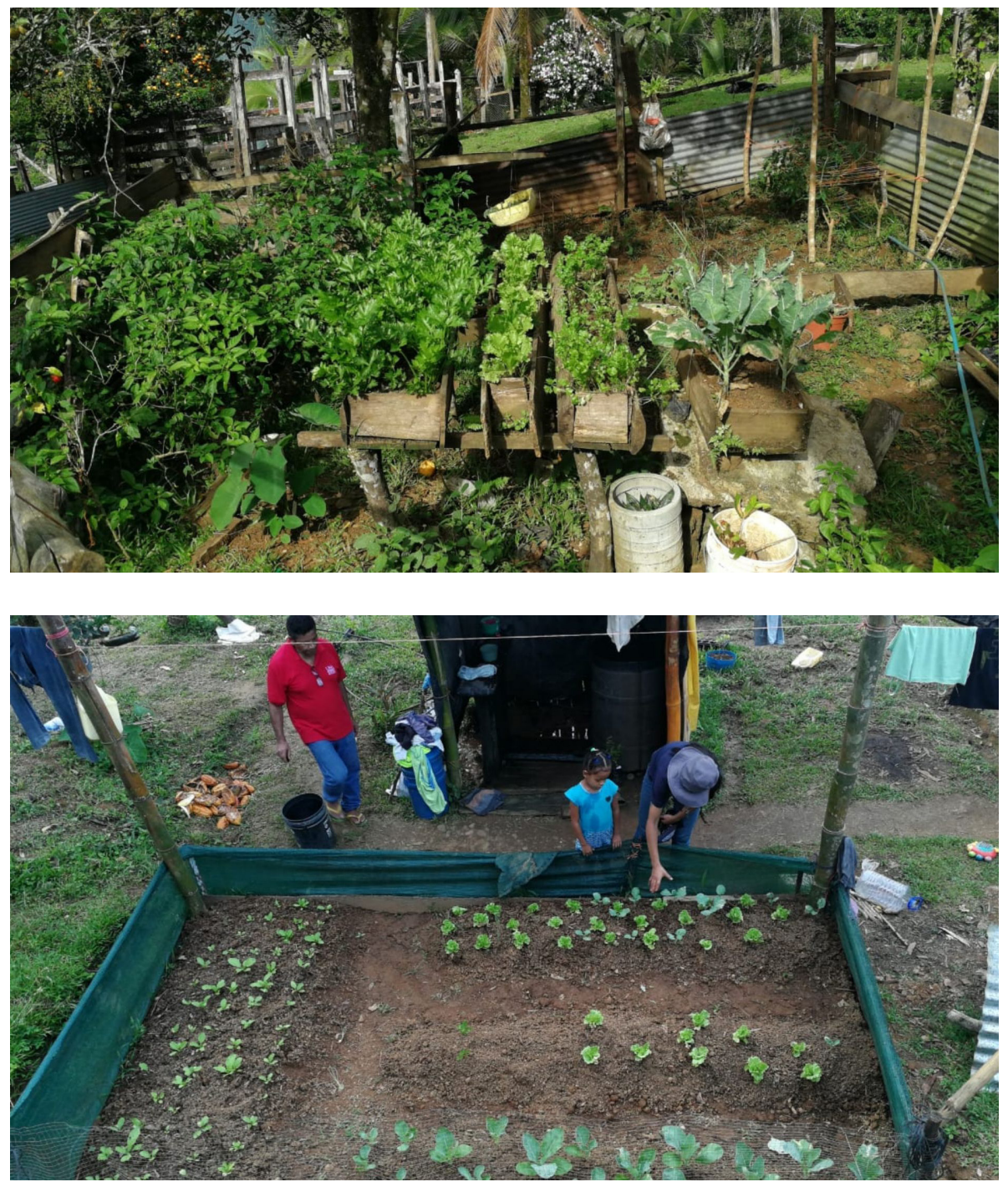

Nota. Imágenes propiedad de las personas autoras. 
URL: http://www.revistas.una.ac.cr/index.php/dialogo/index

CORREO ELECTRÓNICO: universidadendialogo@una.cr

DOI: http://doi.org/10.15359/udre.11-2.8

\section{Figura 5}

Imágenes de los resultados obtenidos en el intercambio comunitario de semillas y alimentos para promover una seguridad alimentaria solidaria entre familias
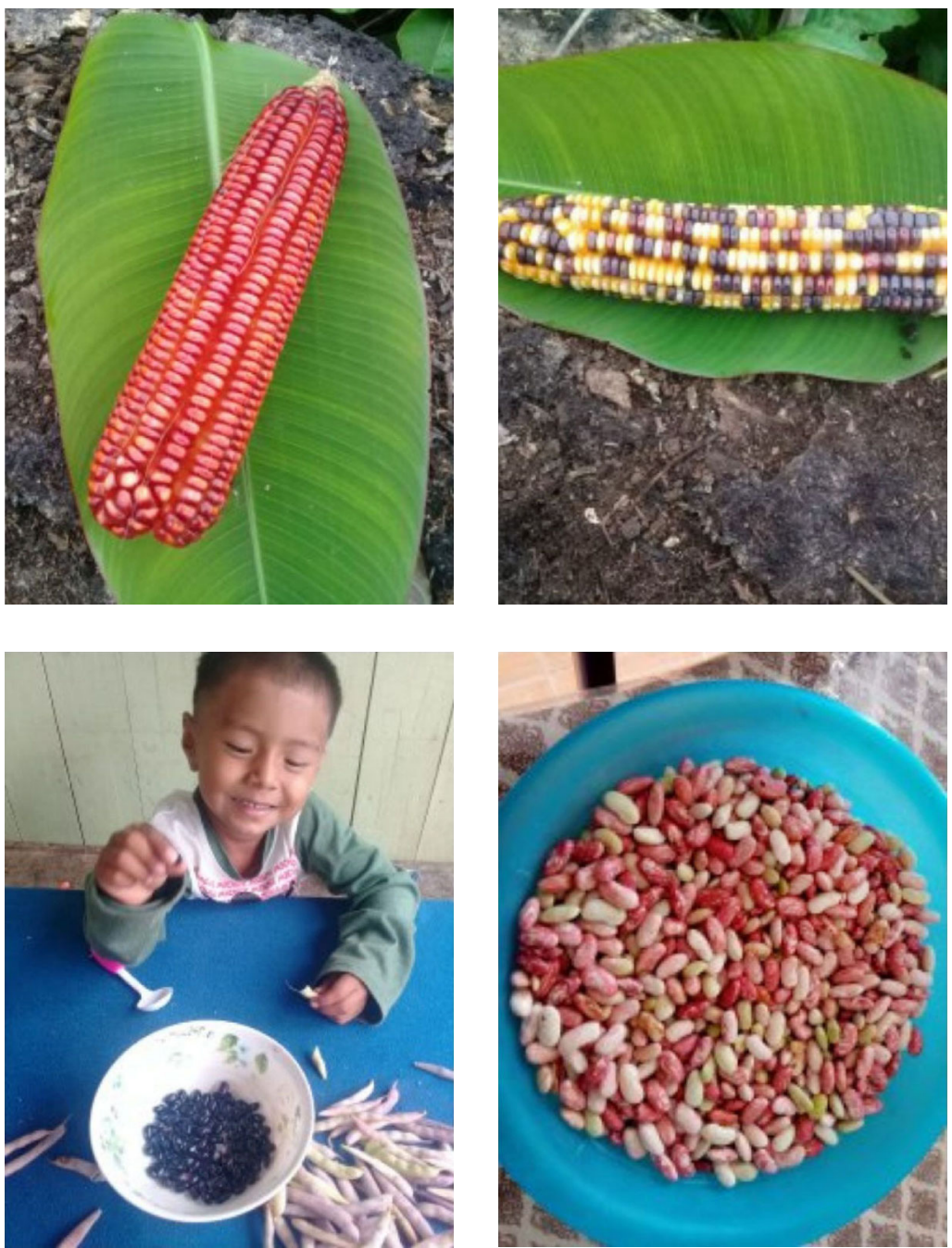

Nota. Imágenes propiedad de las personas autoras. 
El proyecto logró implementar los siguientes cultivos: frijol negro, frijol de mantequilla, frijol rojo, frijol blanco, frijol nazareno, plátano, banano, ajonjolí, cas, cacao, piña, flor de Jamaica, zacate de limón, canavalia roja, yuca, cinco variedades de maíz, incluido uno azteca, papa malanga, pipián, ayote, cebolla, manzana de agua, manzana rosa, zanahoria, naranja y frijol de soja. Otros cultivos que se introdujeron son zanahoria, variedades de chile, como el panameño, albahaca y plantas medicinales.

Los resultados demuestran que la introducción diversificada de nuevos cultivos en la unidad de producción familiar se vuelve una alternativa para la seguridad alimentaria y nutricional, la soberanía alimentaria, el combate del desempleo y la pobreza y contra el hambre de los sectores más vulnerables.

Estos resultados permiten visualizar que este tipo de proyectos SAN son claves para el futuro de la alimentación mundial, en el cual las mujeres, los niños, las niñas y las poblaciones indígenas se convertirán en el propulsor de una agricultura familiar sostenible, equitativa, autóctona y amigable con el ambiente (Jara, Rodríguez y Arce, 2020).

\section{Conclusiones}

Los resultados demuestran que se puede producir una gran diversidad de alimentos a nivel de las unidades de producción familiar, también permiten comprender que la agricultura puede desarrollar otra manera de producir alimentos de un modo mucho más sustentable para generar procesos de seguridad alimentaria y nutricional y soberanía alimentaria de las familias y las comunidades.

Es posible lograr una sustentabilidad si conseguimos comunidades más solidarias que trabajen en conjunto y logren economías locales, para así lograr que las poblaciones conserven sus propias prácticas de producción y diversidad de alimentos para la seguridad alimentaria y nutricional y su soberanía alimentaria.

Los resultados permiten proyectar que el empoderamiento de las familias y el apoyo institucional a la estrategia de diversidad de producción de cultivos de seguridad alimentaria y nutricional y soberanía alimentaria son fundamentales para mejorar la cantidad y calidad alimenticia de las familias, y pueden llegar a ser una fuente de ingresos por la venta de excedente bajo un modelo de microagronegocio familiar.

El compromiso y la constancia de las treinta y cuatro familias, junto con el apoyo institucional, fue el pilar fundamental para obtener los resultados satisfactorios del proyecto. 


\section{Recomendación}

Es fundamental que la Universidad Nacional y la institucionalidad pública sigan fomentando y apoyando los proyectos de seguridad alimentaria y nutricional y soberanía alimentaria en las comunidades rurales de nuestro país, lo cual es clave para mejorar la calidad de vida de las personas, y se puede proyectar como una política para combatir el desempleo y la pobreza rural.

\section{Referencias}

FAO, FIDA, OPS, WFP y Unicef. (2020). Panorama de la seguridad alimentaria y nutrición en América Latina y el Caribe 2020. Santiago, Chile.

FAO. (2020). Informe señala a 27 países susceptibles de sufrir crisis alimentarias a causa de la covid-19. Organización de las Naciones Unidas para la Alimentación y la Agricultura (FAO). http://www.fao. org/news/story/es/item/1298478/icode/

FAO. (2006). Seguridad alimentaria y nutricional. Conceptos básicos. http:// www.fao.org/3/a-at772s.pdf

Jara, D., Rodríguez, J., Arce, A. (2020). Plan Nacional de Agricultura y Ganadería. Ministerio de Agricultura y Ganadería (MAG). San José, Costa Rica.

Plan Regional de Desarrollo Agropecuario y Rural 2015-2018. (2015). Comité Sectorial Agropecuario Regional (COSAR). San José, Costa Rica.

Rosset, P. y Altieri, M. (2018). Agroecología, ciencia y política. Barcelona, España: Icaria. 